\title{
谷子对干旱胁迫的生理生态响应
}

\author{
严加坤 $^{1, *}$, 张宁宁 ${ }^{1}$, 张岁岐 ${ }^{2}$ \\ 1 榆林学院生命科学学院, 榆林 719000 \\ 2 中国科学院水利部水土保持研究所土壤侵蚀与旱地农业国家重点实验室, 杨凌 712100
}

摘要:干旱少雨严重限制了我国西北地区谷子的产量, 为明确谷子响应干旱的生理特征,以干旱敏感谷子品种安 04 和不敏感品 种豫谷 1 号以及 xiaomi 为材料, 通过盆栽试验, 研究了谷子不同生育期叶片光合参数、叶绿素含量、非结构性碳、 $\beta$-淀粉酶基因 表达对水分亏缺的响应。结果表明,正常水分条件下安 04 产量高于豫谷 1 号, 干旱胁迫严重限制了两个谷子品种的产量形成, 安 04 和豫谷 1 号分别减产 $71.2 \%$ 和 $56.0 \%$, 豫谷 1 号产量显著高于安 04 。正常水分条件下,安 04 具有比豫谷 1 号更高的净光 合速率 $(P<0.05)$, 干旱胁迫下, 豫谷 1 号叶片净光合速率显著高于安 04 ; 叶片蒸腾速率结果同光合结果一致。干旱条件下, 豫 谷 1 号具有更高的叶片相对含水量。干旱胁迫显著降低了两个谷子品种花期的叶绿素 $\mathrm{a}$ 、叶绿素 $\mathrm{b}$ 及总叶绿素含量, 且安 04 降 低幅度均大于豫谷 1 号。干旱胁迫均显著增加了豫谷 1 号拔节期和开花期的叶片可溶性糖含量, 而安 04 叶片可溶性糖含量并 没有发生显著性变化, 同时干旱胁迫显著增加了豫谷 1 号 $\beta$-淀粉酶基因 SiBAM 1 的表达水平。施用 $\beta$-淀粉酶活性抑制剂 $\alpha$ 环糊精, xiaomi 叶片可溶性糖及脯氨酸含量显著降低,进一步加重了干旱对 xiaomi 的生长抑制。综上所述, 干旱胁迫诱导谷子 $\beta$-淀粉酶基因表达和 $\beta$-淀粉酶活性升高从而水解淀粉形成可溶性糖, 高可溶性糖含量对谷子提高抗旱性起重要作用。

关键词: 谷子; 光合参数; 非结构性碳; $\beta$-淀粉酶

\section{Physiological and ecological responses of foxtail millet to drought stress}

\author{
YAN Jiakun ${ }^{1, *}$, ZHANG Ningning ${ }^{1}$, ZHANG Suiqi ${ }^{2}$ \\ 1 College of Life Science, Yulin University, Yulin 719000, China \\ 2 State Key Laboratory of Soil Erosion and Dryland Farming on the Loess Plateau, Institute of Soil and Water Conservation, Chinese Academy of Sciences and \\ Ministry of Water Resources, Yangling 712100, China
}

\begin{abstract}
Foxtail millet (Setaria italica L.) is an important commercial crop in north China, especially northwest China. However, the uneven distribution of precipitation induce severe seasonal drought and drought seriously limits the yield production of foxtail millet. To clarify physiological characteristics of different genotypes of foxtail millet cultivars in response to drought stress, drought resistance cultivar (Yugu 1) and drought sensitive cultivar (An 04) and xiaomi were selected as materials to detect and compare the photosynthetic parameters, chlorophyll content, non-structure carbohydrate, gene expression of beta-amylase (SiBAM1) at one or three growth periods (jointing, anthesis and ten days after anthesis stage) through a pot experiment carried out in the rainproof shed. Results showed that under normal soil water condition, the An 04 held higher grain yield than Yugul cultivar. Drought stress severely restricted the yield formation of two cultivars. while the yield of An 04 was reduced by $71.2 \%$, and that of Yugu 1 was reduced by 56.0\%. And Yugu1 cultivar had higher grain yield that An 04 under drought condition. Under normal soil water conditions, An 04 had a higher net photosynthetic rate than Yugu $1(P<0.05)$. while under drought stress, the leaf net photosynthetic rate of Yugu 1 was significantly higher than that of An 04 at these three detected growth stages. Leaf transpiration rate was consistent with that of leaf photosynthetic
\end{abstract}

基金项目:国家自然科学基金项目(31960223); 榆林市科学技术协会项目(20190126); 陕西省重点研发计划(2021NY-101)

收稿日期:2020-08-02; 网络出版日期:2021-07-05

* 通讯作者 Corresponding author.E-mail: himingse@163.com 
rate. However, the Yugul held higher leaf relative water content than An 04 under drought condition. Drought stress significantly reduced the chlorophyll a, chlorophyll b and total chlorophyll contents of the two cultivars, while the decrease range of An 04 was greater than that of Yugu 1 especially at anthesis stage. Drought stress significantly increased the soluble sugar content in Yugu 1 leaves at the stage of jointing and anthesis stage, while there was no significant change in the soluble sugar content in the leaves of An 04. Drought stress significantly increased the expression level of SiBAM1 in Yugu 1 gene. Application of $\alpha$-cyclodextrin, an inhibitor of $\beta$-amylase activity, further increased the inhibition of drought on the growth of millet xiaomi, and the contents of leaf soluble sugar and proline decreased significantly compared with none $\alpha$ cyclodextrin application. In summary, drought stress induced the increase of $\beta$-amylase gene expression and $\beta$-amylase activity in foxtail millet, which could take part in hydrolyzing starch into soluble sugar, and the increased soluble sugar played an important role in improving drought resistance of foxtail millet.

Key Words : Setaria italica L.; photosynthetic parameters; none structured carbon; beta-amylase

水分不足是限制干旱半干旱地区农业生产的重要环境因素之一 ${ }^{[1]}$, 植物在长期的适应干旱过程中进化 出一系列的生理生化反应来响应环境水分变化 ${ }^{[2-3]}$ 。谷子 (Setaria italica L.) 是我国起源的特色作物,由于其 具有较高营养价值, 所以在全民营养危机 ${ }^{[4]}$ 及种植业结构调整的大背景下再次成为我国西北干旱半干旱地 区广泛种植的经济作物 ${ }^{[5]}$ 。但由于西北地区降雨量小、月际分布不均, 水分不足严重影响谷子产量, 限制了 谷子产业的发展。因此,提高谷子的耐旱性并进行耐旱育种已成为保障谷子高产稳产的重要途径。

叶片光合作用是植物维持生长的物质基础。干旱引起植物叶片气孔导度的降低, 进而降低蒸腾速率, 减 少叶片蒸腾以改善植物水分状态; 然而这种调节会阻碍 $\mathrm{CO}_{2}$ 进入叶片, 最终由于气孔限制影响光合作用 ${ }^{[6]}$ 。 研究显示, 提高干旱胁迫下高粱叶片气孔导度能有效提高其净光合速率 ${ }^{[7]}$ 。但干旱胁迫妨碍光合色素的正 常合成,并且会加速其分解, 最终导致叶绿素含量下降。目前, 不充分灌溉的灌溉制度导致玉米叶片叶绿素含 量显著降低 ${ }^{[8]}$, 因此, 提高干旱胁迫下植物叶片叶绿素含量对维持光合作用具有重要意义。另外,干旱胁迫 会降低作物光系统 II 的光化学效率, 影响作物体内活性氧自由基代谢和脂膜流动性; 通常植物通过增加可溶 性糖和氨基酸含量(如: 脯氨酸等) 来调节细胞渗透势, 进而达到应对干旱胁迫的目的 ${ }^{[9]}$ 。干旱显著提高谷子 叶片脯氨酸、可溶性总糖、和淀粉含量以提高其抗旱性 ${ }^{[9]}$ 。其中, 可溶性糖和淀粉构成的非结构性碳在植物 应对非生物胁迫如:干旱、温度、光照及盐害中起重要作用 ${ }^{[10-13]}$ 。研究表明:干旱胁迫诱导玉米叶片非结构性 碳积累提高玉米综合抗旱性, 且抗旱能力较强的玉米品种在干旱条件下具有更强的非结构性碳积累能力 ${ }^{[14]}$ 。 刘亚静等 ${ }^{[9]}$ 对大气 $\mathrm{CO}_{2}$ 浓度升高和干旱互作对谷子生长的研究中发现, 干旱胁迫下 $\mathrm{CO}_{2}$ 浓度升高提高了可溶 性糖含量, 降低了淀粉含量从而缓解干旱胁迫对谷子的生长抑制。可见, 可溶性糖积累对谷子抗旱性的提高 具有重要作用。对谷子的转录组数据分析显示, 干旱条件下谷子 $\beta$-淀粉酶基因表达剧烈上调 ${ }^{[15]}$, 而 $\beta$-淀粉 酶正是淀粉水解形成可溶性糖的直接催化剂。由此说明, 非结构性碳组成 (淀粉/可溶性糖) 可能是影响谷子 抗旱性的重要因素。

长期以来,围绕谷子适应干旱机理方面国内外做了大量研究,取得了重要的研究成果,如干旱下谷子气孔 调控机理 ${ }^{[16]}$ 、篮选出一批重要的抗旱基因 ${ }^{[17-19]}$ 。然而大部分研究主要集中在苗期渗透胁迫等 ${ }^{[20]}$ 方面, 对干 旱条件下谷子重要生育期光合响应特征及非结构性碳代谢缺少深人研究, 而谷子是我国典型的抗旱耐痊特色 作物, 因此研究谷子的抗旱过程中光合及碳代谢响应机制具有重要理论意义。本文拟采用盆栽控水的方法, 研究 (1) 不同抗旱性谷子品种响应干旱胁迫的光合特征, 功能叶片非结构性碳组成及相关基因表达情况, (2) 外源施用 $\beta$-淀粉酶活性抑制剂 $\alpha$-环糊精 ${ }^{[21]}$ 条件下谷子各生理指标的变化旨在为进一步分析探索碳代谢在 谷子逆境应答中的功能和机制提供一些有益线索。 


\section{1 材料与方法}

\section{1 试验材料及设计}

(1) 试验 1 不同抗旱性谷子品种干旱适应特征研究

以干旱敏感谷子品种安 04(An04) 和抗旱性较强的品种豫谷 1 号 (Yugu1) 为材料 ${ }^{[15]}$, 试验所用种子由山 西农业大学农学院韩淵怀教授提供。

试验在防雨棚内进行, 试验材料种植在圆柱形塑料桶 (高 $30 \mathrm{~cm}$, 直径 $30 \mathrm{~cm}$ ) 内, 试验所用土壤为大田 20 $\mathrm{cm}$ 表层的黄绵土(有机质 $3.2 \mathrm{~g} / \mathrm{kg}, \mathrm{pH} 8.6$, 全氮 $0.3 \mathrm{~g} / \mathrm{kg}$, 全磷 $0.5 \mathrm{~g} / \mathrm{kg}$, 全钾 $18.3 \mathrm{~g} / \mathrm{kg}$, 碱解氮 $16.1 \mathrm{mg} / \mathrm{kg}$, 速效磷 $4.8 \mathrm{mg} / \mathrm{kg}$, 速效钾 $65.8 \mathrm{mg} / \mathrm{kg}$ ), 每桶装人风干土 $8.5 \mathrm{~kg}$, 基础肥料施用同当地生产水平一致, 在拔节 期追肥。种子均匀点播于土壤表层 $2 \mathrm{~cm}$ 处,每个品种种植 30 盆、共 60 盆,并且控制土壤含水量为田间持水 量 75\% 5 \% , 每天 18:00 通过人工称重补充水分。待幼苗长至 3 叶期选取长势一致的幼苗定苗至每盆 4 株, 土壤表面添加 $2 \mathrm{~cm}$ 高蛭石保水, 同时开始控水试验。试验设置正常供水组 (WW) : 保持土壤水分为田间持水 量 75\% 5 \% , 干旱处理组 (WD) : 3 叶期后保持土壤水分为田间持水量 35\% 5 \% 。分别在拔节期和开花期取 样进行生理指标测定, 在成熟期测产。

(2) 试验 $2 \beta$-淀粉酶功能验证

为验证 $\beta$-淀粉酶在谷子抗旱中的作用设计试验 2 , 以山西农业大学最新创制 $x i a o m i^{[22]}$ 为材料,在室内人 工气候箱进行。试验材料种植在圆形塑料桶 (高 $15 \mathrm{~cm}$, 直径 $10 \mathrm{~cm}$ ) 内, 试验所用土壤为草炭土 (Pindstrup Mosebrug A/S, Ryomgaard, Denmark), 播种方法同试验 1 ; 种子出苗后每盆定苗 3 株, 长至 3 叶期开始干旱处 理。试验设置四组:正常供水组 (WW) : 保持充分供水;正常供水 $+\alpha$-环糊精组 (WW $\alpha$ ) : 保持充分供水并且每 两天叶片喷施 $20 \mathrm{mmol} / \mathrm{L} \alpha$-环糊精; 干旱处理组 (WD) : 停止浇水, 自然干旱; 干旱处理 $+\alpha$-环糊精组 (WD $\alpha)$ : 停止浇水并且每两天叶片喷施 $20 \mathrm{mmol} / \mathrm{L} \alpha$-环糊精。 $\alpha$-环糊精喷施以沾湿叶片为准, 对照喷施相同剂量的纯 净水。试验处理 10 天后进行各生理指标的测定。

1.2 测定内容和方法

\subsection{1 生物量、测产及相关指标}

试验 1 : 在拔节期和开花期分别取 5 株测定地上部生物量。取地上部分分别装入样品袋, $105{ }^{\circ} \mathrm{C}$ 杀青 25 $\min , 75{ }^{\circ} \mathrm{C}$ 烘干至恒重后称重, 即为地上部生物量。在成熟期测产, 地上部分按盆收取之后 $75{ }^{\circ} \mathrm{C}$ 烘干至恒重 后称重即为地上部生物量, 之后手工脱粒称取粒重, 即为每盆产量。通过人工数粒测定千粒重。在花后 15 天 用卷尺测量植株拉直后的最大高度作为株高, 每处理重复 10 次。用直尺测定旗叶长度并测定最宽处的宽度。

试验 2 : 取 8 株测定地上部生物量, 方法同试验 1 。

\subsection{2 光合参数及叶片指标}

试验 1 : 光合参数采用 Li-6400 便携式光合仪( LICOR Inc., Lincoln, NE, USA) , 分别在拔节期、开花期及 花后 10 天测定。具体方法为:在晴天 10:00-1:00 am 测定完全展开的新叶 (拔节期)、旗叶 (开花期及花后 10 天) 的净光合速率、气孔导度和蒸腾速率, 测定参数设 定为光量子密度 $1000 \mu \mathrm{mol} \mathrm{m} \mathrm{m}^{-2} \mathrm{~s}^{-1}$ 、流量 $500 \mu \mathrm{mol} / \mathrm{s}$ 、 叶温 $28{ }^{\circ} \mathrm{C}$ 。采用 PhotosynQ MultispeQ V2 ${ }^{[23]}$ 测定仪测 定光系统 II 最大化学效率 $(\mathrm{Fv} / \mathrm{Fm})$; 采用乙醇浸提比 色法 ${ }^{[24]}$ 测定拔节期新叶及开花期旗叶叶绿素含量; 采 用硫酸葱酮比色法 ${ }^{[24]}$ 测定可溶性糖和淀粉含量; 采用

\section{表 1 实时定量 PCR 所用引物信息}

Table 1 The primers of the $\operatorname{SiBAM}$ genes and reference gene

\begin{tabular}{ccl}
\hline $\begin{array}{c}\text { 基因位点 } \\
\text { Gene ID }\end{array}$ & $\begin{array}{c}\text { 基因 } \\
\text { Gene }\end{array}$ & $\begin{array}{l}\text { 引物序列 } \\
\text { Primer sequence }\end{array}$ \\
\hline Si035044m & SiBAM1a & $\begin{array}{l}\text { F5'-GATGGTGGCGTTCACGTA-3' } \\
\text { R5'-AAAGAAAACCCCTACACAAAGC-3' }\end{array}$ \\
Si034946m & SiBAM1 $b$ & F5'-CGATCTCTAGACGGTGATACAC-3' \\
& & R5'-GCTTCCTTTCCCTTCTTACACT-3' \\
& \multirow{2}{*}{ SiActing } & F5'-CGCATATGTGGCTCTTGACT-3' \\
& & R5'-GGGCACCTAAATCTCTCTGC-3' \\
\hline
\end{tabular}

SiBAM1a: 谷子 $\beta$-淀粉酶 1a Setaria italica $\beta$-amylase 1a; $S i B A M 1 b$ : 谷子 $\beta$-淀粉酶 $1 \mathrm{~b}$ Setaria italica $\beta$-amylase $1 \mathrm{~b}$ Barrs and Weatherley 方法 ${ }^{[25]}$ 测定叶片相对含水量。 
开花期取样,液氮冷冻后放人超低温冰箱 $-80{ }^{\circ} \mathrm{C}$ 保存备用,试验所用引物序列见表 1 。

采用全式金 EasyPure ${ }^{\circledR}$ Plant RNA Kit 提取总 RNA, 经 EasyScript ${ }^{\circledR}$ One-Step gDNA Removal and cDNA Synthesis SuperMix 反转录后使用 TransStart ${ }^{\circledR}$ Tip Green qPCR SuperMix 利用 FTC-3000P 实时苂光定量 PCR 仪进行实时定量测定,数据采用 $2^{-\Delta \Delta \mathrm{Ct}[26]}$ 法计算。

试验 2 : 采样后分别测定 $\beta$-淀粉酶活性 ${ }^{[27]}$, 淀粉和可溶性糖含量 ${ }^{[24]}$ 及脯氨酸 ${ }^{[2]}$ 含量。

1.3 数据处理

利用 SPSS 19.0 进行 ANOVA 方差分析, 用最小显著差异法 (LSD) 进行多重比较, 显著性水平为 $P=0.05$ 。 采用 Sigmaplot12.5 绘图。

\section{2 结果与分析}

2.1 干旱对两个品种谷子生物量、产量及相关性状的影响

由表 2 可知, 干旱胁迫严重限制了两个谷子品种的产量形成 (安 04 和豫谷 1 号分别减产 $71.2 \%$ 和 $56.0 \%$ ，但其对不同品种的生物量和产量的影响程度不同。正常水分条件下,两个谷子品种地上部生物量在 拔节期和开花期均不存在显著性差异 $(P>0.05)$; 而干旱胁迫下, 豫谷 1 号的地上部生物量显著高于安 04 的 地上部生物量 $(P<0.05)$ 。在成熟期,正常水分条件下, 安 04 的生物量和产量比豫谷 1 号分别高 $7.1 \%$ 和 $12.4 \%$; 但干旱胁迫下, 豫谷 1 号具有更高的生物量和产量, 比安 04 分别高 $27 \%$ 和 $35.7 \%(P<0.05)$, 表明豫谷 1 号比安 04 具有更强的维持产量的能力; 但干旱胁迫并没有对两个谷子品种千粒重产生显著性影响 $(P>$ $0.05)$ 。

\section{表 2 不同水分条件下两个谷子品种谷子产量及其相关性状}

Table 2 Yield and its related characters of two millet cultivars under different water conditions

\begin{tabular}{|c|c|c|c|c|c|c|}
\hline \multirow{2}{*}{\multicolumn{2}{|c|}{$\begin{array}{c}\text { 处理 } \\
\text { Treatment }\end{array}$}} & \multicolumn{3}{|c|}{ 生物量 Biomass/(g/株) } & \multirow{3}{*}{$\begin{array}{c}\text { 千粒重 } \\
1000 \text {-grain yield/g } \\
3.27 \pm 0.13 \mathrm{a}\end{array}$} & \multirow{3}{*}{$\begin{array}{c}\text { 产量 } \\
\text { Grain yield/(g/株 }) \\
6.42 \pm 0.29 \mathrm{a}\end{array}$} \\
\hline & & \multirow{2}{*}{$\begin{array}{c}\begin{array}{c}\text { 拔节期 } \\
\text { Jointing stage }\end{array} \\
2.35 \pm 0.16 \mathrm{a}\end{array}$} & \multirow{2}{*}{$\begin{array}{c}\begin{array}{c}\text { 开花期 } \\
\text { Anthesis stage }\end{array} \\
9.33 \pm 0.52 \mathrm{a}\end{array}$} & \multirow{2}{*}{$\begin{array}{c}\text { 成熟期 M } \\
\text { aturation stage }\end{array}$} & & \\
\hline WW & 安 04 & & & & & \\
\hline \multirow{3}{*}{ WD } & 豫谷 1 号 & $2.01 \pm 0.29 \mathrm{a}$ & $9.56 \pm 0.27 \mathrm{a}$ & $15.30 \pm 0.41 \mathrm{~b}$ & $2.73 \pm 0.07 \mathrm{~b}$ & $5.71 \pm 0.21 b$ \\
\hline & 安 04 & $1.25 \pm 0.12 b$ & $5.05 \pm 0.23 \mathrm{c}$ & $7.27 \pm 0.14 \mathrm{~d}$ & $3.20 \pm 0.2 \mathrm{a}$ & $1.85 \pm 0.08 \mathrm{~d}$ \\
\hline & 豫谷 1 号 & $1.90 \pm 0.13 \mathrm{a}$ & $6.03 \pm 0.27 b$ & $8.54 \pm 0.45 c$ & $2.53 \pm 0.07 b$ & $2.51 \pm 0.04 \mathrm{c}$ \\
\hline
\end{tabular}

不同字母代表显著性差异 $(P<0.05)$; WW : 正常供水 Well-watered;WD : 水分匮缺 (干旱) Water deficit

干旱胁迫显著降低了两个谷子品种的株高和旗叶叶长(图 1), 其中安 04 株高下降幅度 (30.8\%) 大于豫 谷 1 号下降幅度 $(21.2 \%)$; 虽然干旱胁迫显著降低了旗叶叶长, 但品种种间并不存在显著性差异 $(P>0.05)$ 。 干旱胁迫虽显著降低了安 04 的旗叶宽度 $(P<0.05)$, 但其对豫谷 1 号并没有产生显著性影响 $(P>0.05)$ 。

2.2 干旱对两个谷子品种谷子叶片光合及水分参数的影响

两个谷子品种的叶片净光合速率在各生育期均呈现出相似的变化趋势 (图 2)。正常水分条件下,安 04 的叶片净光合速率高于豫谷 1 号, 且在开花期和花后 10 天均达到显著性水平 $(P<0.05)$; 但干旱胁迫下, 豫谷 1 号的叶片净光合速率在不同生育期均显著大于安 $04(P<0.05)$ 。然而, 两个谷子品种的最大光化学效率在 拔节期各处理及各品种间均不存在显著性差异 $(P>0.05)$, 但干旱胁迫下, 开花期及花后 10 天, 豫谷 1 号的最 大光化学效率显著高于安 $04(P<0.05)$ 。

拔节期, 干旱胁迫显著降低了安 04 的叶绿素 $\mathrm{a} 、$ 叶绿素 $\mathrm{b}$ 及总叶绿素含量 (表 3), 而同期豫谷 1 号中仅叶 绿素 $\mathrm{a}$ 表现出显著性降低现象 $(P<0.05)$ 。开花期, 两个谷子品种的叶绿素 $\mathrm{a} 、$ 叶绿素 $\mathrm{b}$ 及总叶绿素含量均出 现显著性降低 (表 3), 但安 04 降幅更大, 其中叶绿素 a、叶绿素 b 及总叶绿素含量分别降低 45.9\%、43.3\% 和 $43.3 \%$, 豫谷 1 号分别降低 $43.9 \% 、 28.2 \%$ 和 $29.1 \%$ 。

图 3 显示, 在两种水分条件下, 两个谷子品种的叶片气孔导度呈现完全相反的现象, 蒸腾速率的变化趋势 

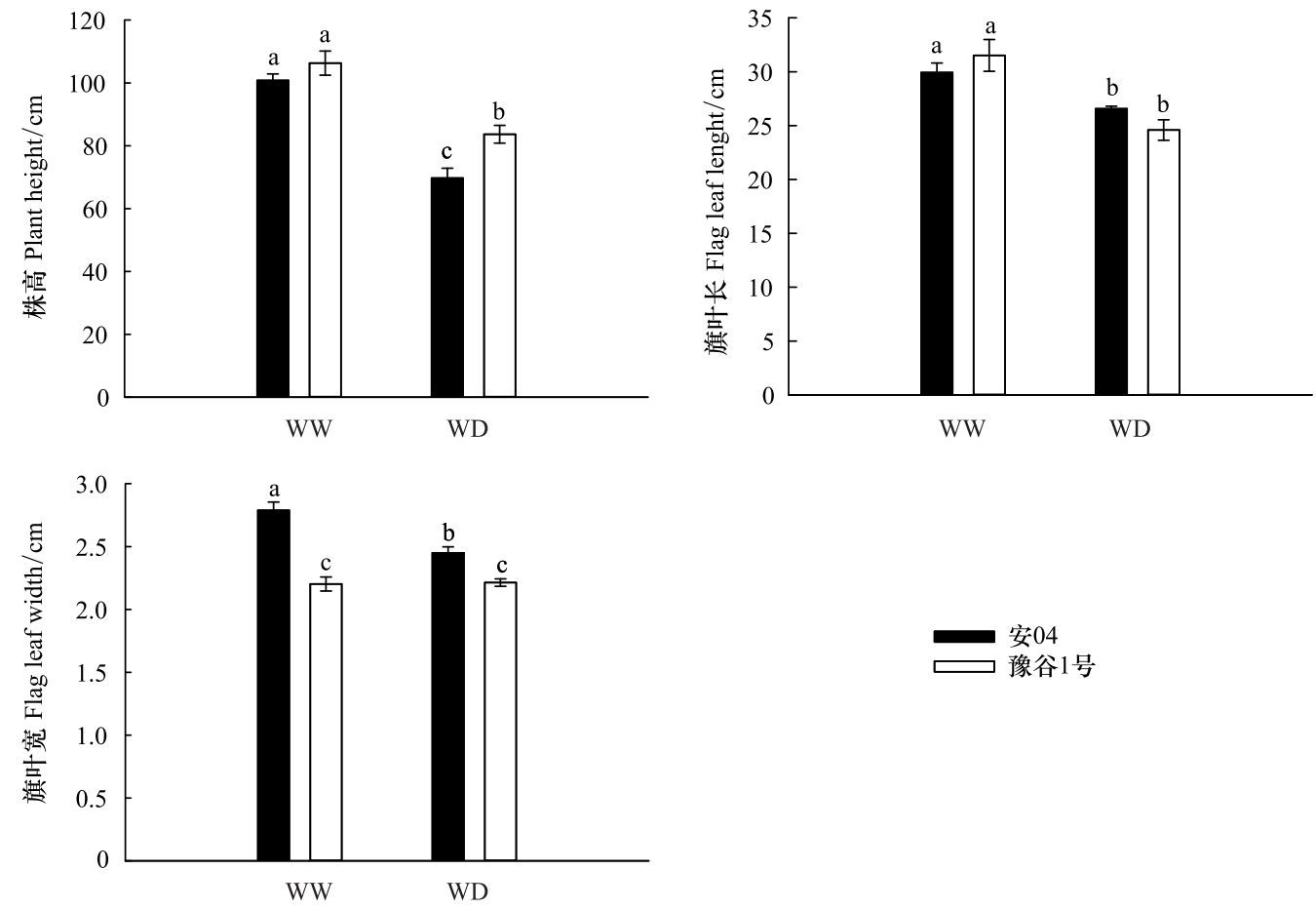

图 1 不同水分条件下两个谷子品种株高、旗叶叶长和叶宽

Fig.1 Plant height, flag leaf length and leaf width of two millet cultivars under different water conditions WW: 正常供水 Well-watered; WD : 水分匮缺(干旱) Water deficit

安 04 豫谷1号

拔节期
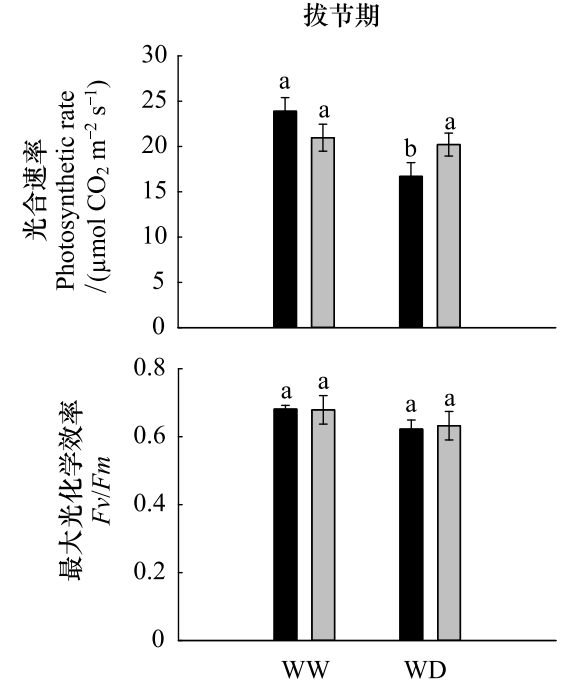

\section{开花期}
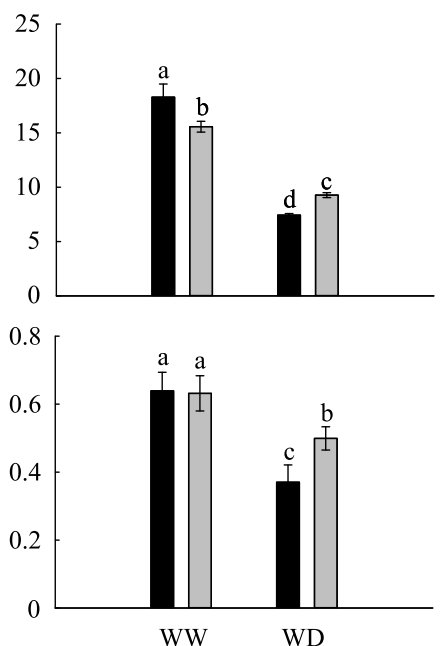

花后 $10 \mathrm{~d}$
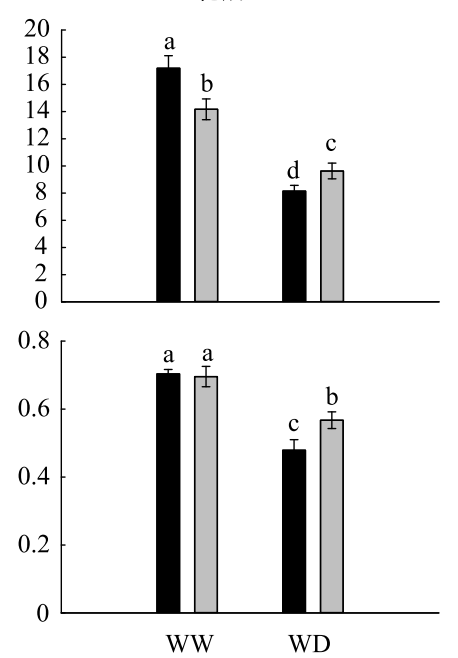

图 2 不同水分条件下两个谷子品种的光合相关参数

Fig.2 Photosynthetic parameters of the two millet cultivars under different water conditions 不同字母代表显著性差异 $(P<0.05)$

与叶片气孔导度完全一致。正常水分条件下,拔节期和开花期安 04 的叶片气孔导度和蒸腾速率均显著大于 豫谷 1 号 $(P<0.05)$ 。而干旱胁迫下, 豫谷 1 号的叶片气孔导度和蒸腾速率均显著大于安 $04(P<0.05)$ 。而两 个谷子品种的叶片相对含水量表现不同,正常水分条件下,拔节期及开花期安 04 和豫谷 1 号叶片相对含水量 无显著性差异 $(P>0.05)$; 但干旱胁迫下, 安 04 叶片相对含水量显著低于豫谷 1 号 $(P<0.05)$ 。 
表 3 不同水分条件下两个谷子品种的叶绿素含量

Table 3 Chlorophyll content of two millet cultivars under different water conditions

\begin{tabular}{|c|c|c|c|c|c|c|c|}
\hline \multirow{2}{*}{\multicolumn{2}{|c|}{$\begin{array}{c}\text { 处理 } \\
\text { Treatment }\end{array}$}} & \multicolumn{2}{|c|}{ 叶绿素 $\mathrm{a}$} & \multicolumn{2}{|c|}{$\begin{array}{c}\text { 叶绿素 b } \\
\text { Chlorophyll b/( mg/g 鲜重) }\end{array}$} & \multicolumn{2}{|c|}{$\begin{array}{c}\text { 总叶绿素 } \\
\text { Total chlorophyll /( mg/g 鲜重) }\end{array}$} \\
\hline & & 拔节期 & 开花期 & $\begin{array}{c}\text { 拔节期 } \\
\text { Jointing stage }\end{array}$ & $\begin{array}{c}\text { 开花期 } \\
\text { Anthesis stage }\end{array}$ & $\begin{array}{c}\text { 拔节期 } \\
\text { Jointing stage }\end{array}$ & \multirow{2}{*}{$\begin{array}{c}\begin{array}{c}\text { 开花期 } \\
\text { Anthesis stage }\end{array} \\
3.93 \pm 0.14 \mathrm{a}\end{array}$} \\
\hline WW & 安 04 & $1.99 \pm 0.02 \mathrm{a}$ & $2.96 \pm 0.11 \mathrm{a}$ & $0.62 \pm 0.01 \mathrm{a}$ & $0.97 \pm 0.03 \mathrm{a}$ & $2.61 \pm 0.02 \mathrm{a}$ & \\
\hline \multirow{3}{*}{ WD } & 豫谷 1 号 & $1.87 \pm 0.08 \mathrm{a}$ & $2.23 \pm 0.07 \mathrm{~b}$ & $0.58 \pm 0.03 \mathrm{ab}$ & $0.71 \pm 0.02 b$ & $2.45 \pm 0.12 \mathrm{ab}$ & $2.95 \pm 0.09 \mathrm{~b}$ \\
\hline & 安 04 & $1.57 \pm 0.06 b$ & $1.60 \pm 0.24 c$ & $0.51 \pm 0.02 b$ & $0.55 \pm 0.10 \mathrm{c}$ & $2.08 \pm 0.07 b$ & $2.23 \pm 0.34 \mathrm{c}$ \\
\hline & 豫谷 1 号 & $1.56 \pm 0.12 \mathrm{~b}$ & $1.58 \pm 0.02 \mathrm{c}$ & $0.53 \pm 0.04 \mathrm{~b}$ & $0.51 \pm 0.01 \mathrm{c}$ & $2.10 \pm 0.12 b$ & $2.09 \pm 0.03 c$ \\
\hline
\end{tabular}

不同字母代表显著性差异 $(P<0.05)$
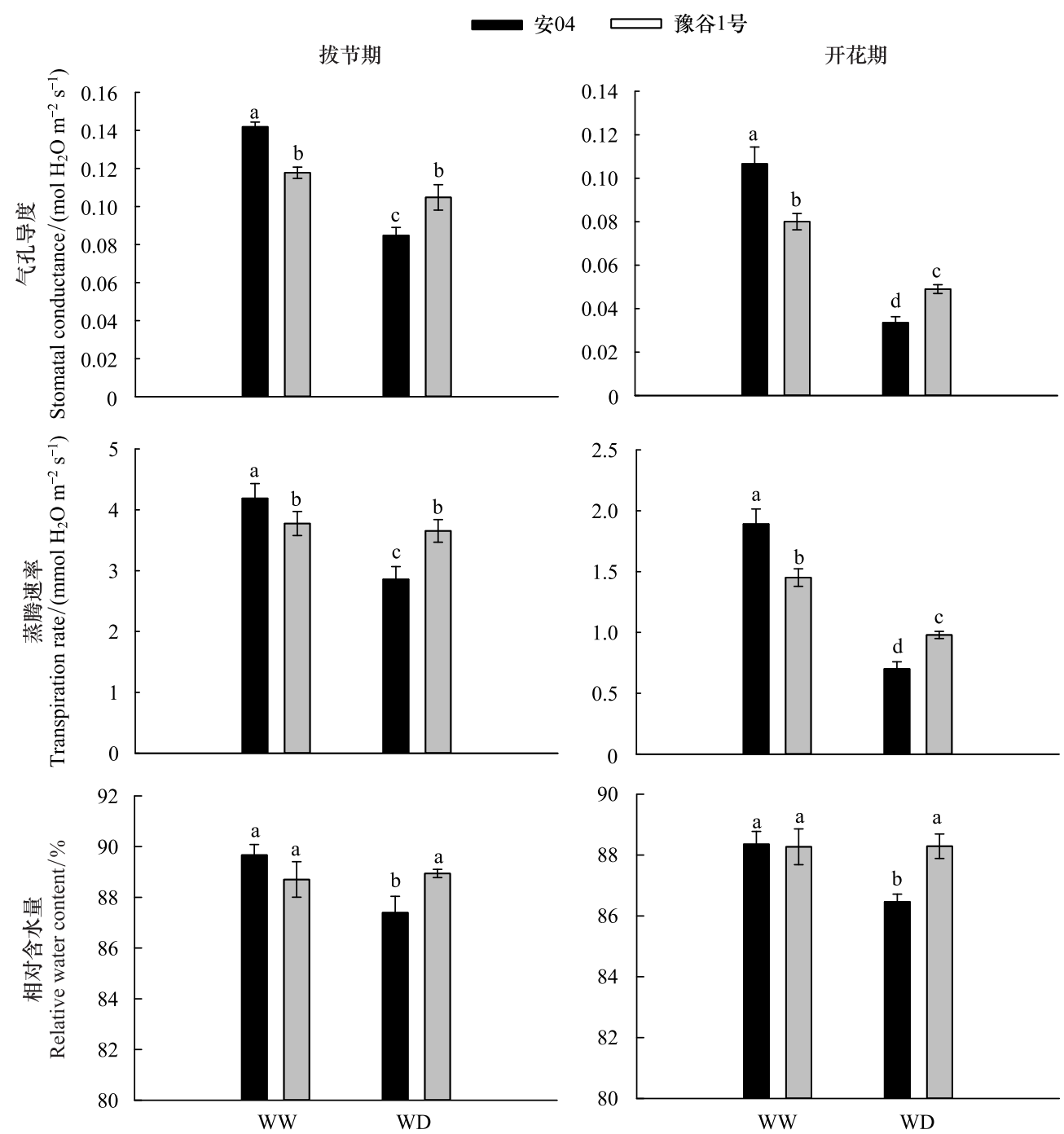

图 3 不同水分条件下两个谷子品种叶片水分参数

Fig.3 Leaf water parameters of two millet cultivars under different water conditions

2.3 叶片非结构性碳及相关基因表达

图 4 显示, 干旱胁迫均显著增加了拔节期和开花期豫谷 1 号的叶片可溶性糖含量 $(P<0.05)$, 但安 04 叶 片可溶性糖含量没有发生显著性变化 $(P>0.05)$ 。然而, 干早胁迫对两个谷子品种叶片淀粉含量的影响显著 不同, 其中拔节期, 干旱胁迫显著性降低了安 04 叶片的淀粉含量 $(P<0.05)$, 但豫谷 1 号叶片的淀粉含量则呈 
现出升高的趋势; 开花期,两个谷子品种叶片的淀粉含量没有表现出显著性差异。同时,干旱胁迫下豫谷 1 号 在拔节期和开花期均表现出更高的叶片非结构性碳的积累 $(P<0.05)$, 而安 04 叶片非结构性碳在两种水分条 件下并不具有显著性差异 $(P>0.05)$ 。
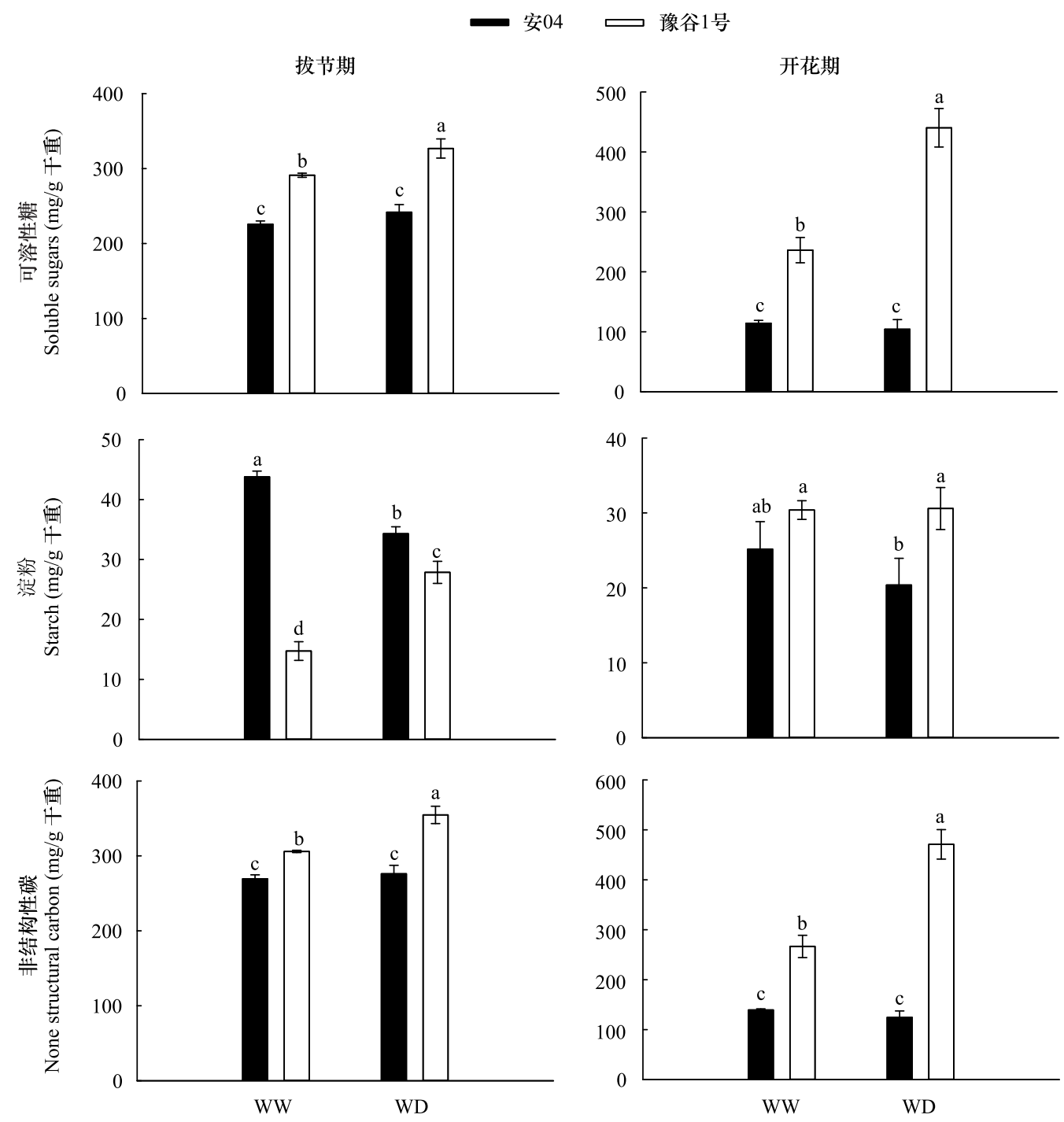

图 4 不同水分条件下两个谷子品种叶片非结构性碳组成

Fig.4 Leaf unstructured carbon of two millet cultivars under different water conditions

开花期旗叶 $\beta$-淀粉酶基因表达结果显示:干旱胁迫显著提高了 SiBAM1 基因表达水平(图 5 )。干旱胁迫 下,安 $04 S i B A M 1 a$ 表达水平为正常水分下 1.80 倍, $S i B A M 1 b$ 为正常水分下 1.78 倍; 豫谷 1 号 SiBAM1 $a$ 表达水 平为正常水分下 4.87 倍, $S i B A M 1 b$ 为正常水分下 6.05 倍。表明干旱胁迫下,豫谷 1 号 $\beta$-淀粉酶基因在旗叶中 表达增量显著高于安 $04(P<0.05)$ 。

\section{$2.4 \beta$-淀粉酶基因功能验证}

如图 6 所示,干旱胁迫显著降低了 $x i a o m i$ 生物量 $(50.7 \%)$, 外源施用 $\alpha$-环糊精进一步加剧了干旱导致的 生长抑制。 $\beta$-淀粉酶活性分析显示,外源施用 $\alpha$-环糊精显著抑制了不同水分条件下 xiaomi 叶片 $\beta$-淀粉酶活 性。而 $\beta$-淀粉酶活性降低导致淀粉水解受到抑制, 表现为干旱胁迫下 xiaomi 叶片具有更高的淀粉含量和更 低的可溶性糖含量。脯氨酸含量结果表明,外源施用 $\alpha$-环糊精显著降低了两种水分条件下的脯氨酸含量。 

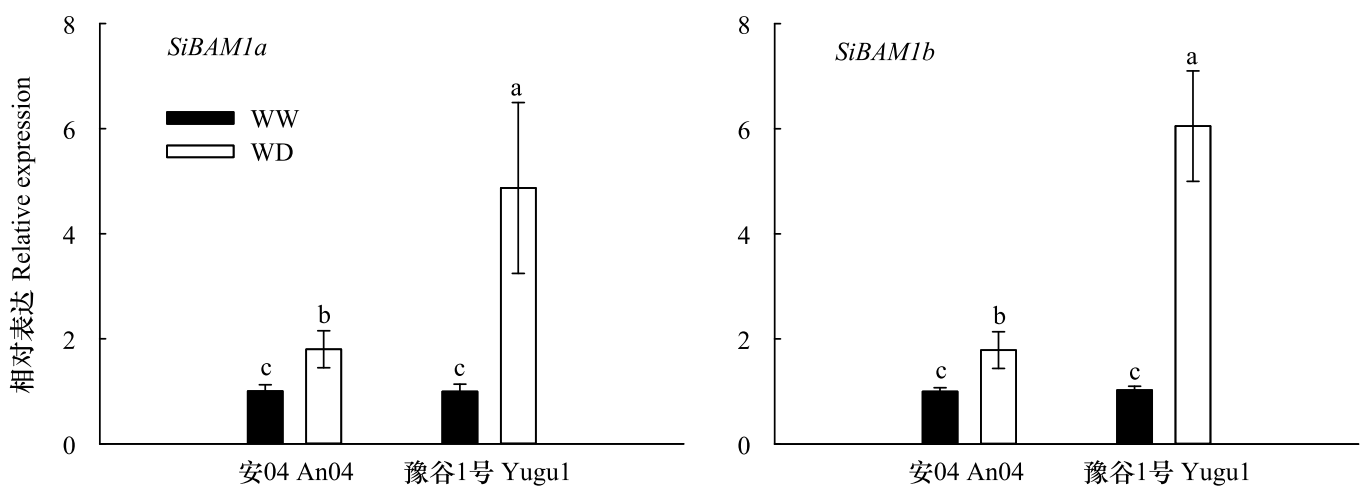

图 5 开花期旗叶 $\boldsymbol{\beta}$-淀粉酶基因表达

Fig.5 Gene expression of $\beta$-amylase in flag leaf at anthesis stage

SiBAM1a: 谷子 $\beta$-淀粉酶 1a Setaria italica $\beta$-amylase 1a;SiBAM1b:谷子 $\beta$-淀粉酶 $1 \mathrm{~b}$ Setaria italica $\beta$-amylase $1 \mathrm{~b}$
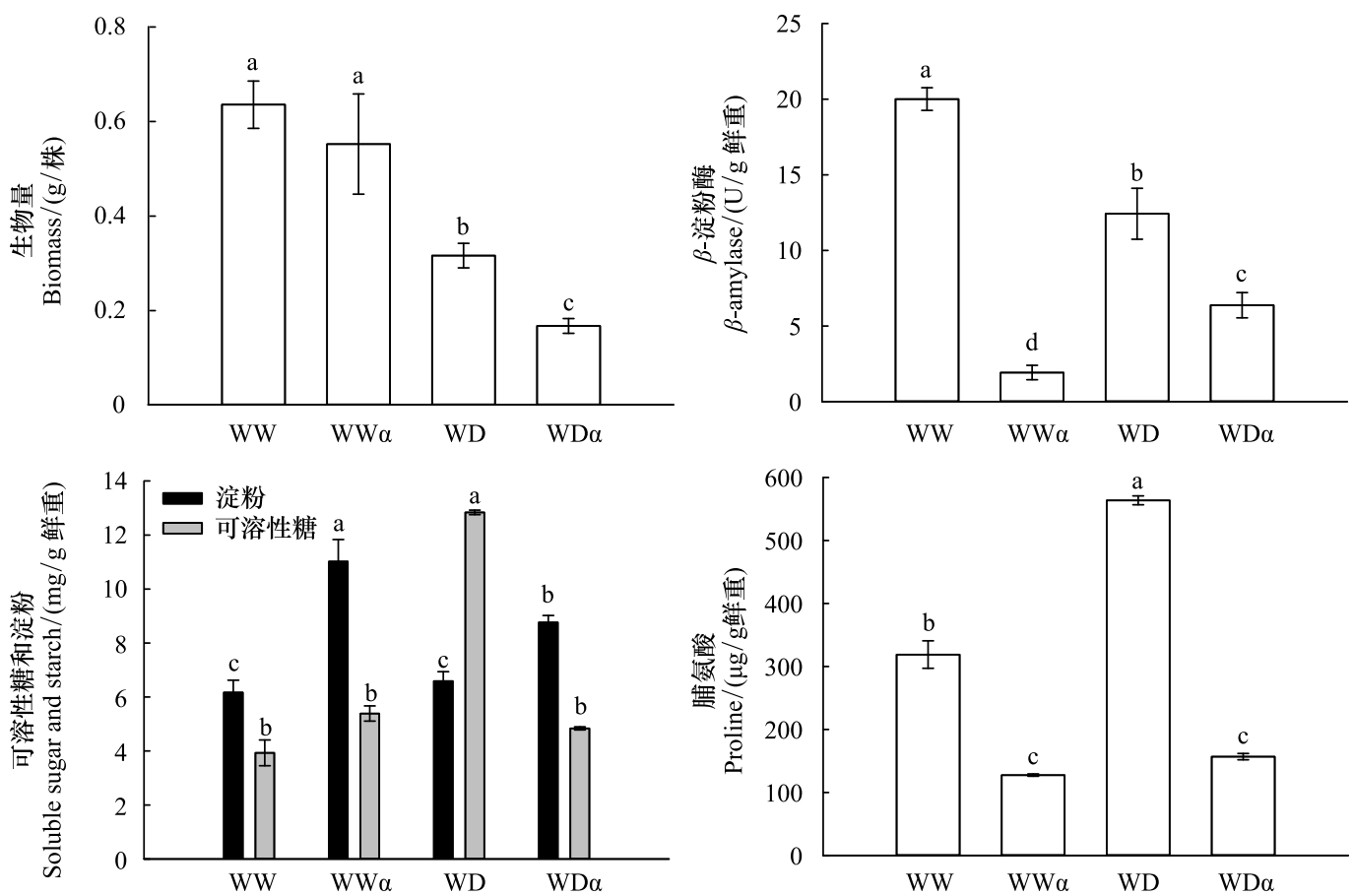

图 6 外源 $\alpha$-环糊精对干旱胁迫下谷子 $x i a o m i$ 生物量、 $\beta$-淀粉酶活性、可溶性糖和淀粉及脯氨酸含量的影响

Fig.6 Effects of exogenous $\alpha$-Cyclodextrin on biomass, $\beta$-amylase activity, soluble sugar, starch and proline content of millet under water deficit condition

$\mathrm{WW} \alpha$ : 正常供水 $+\alpha$-环糊精 Well-watered $+\alpha$-cyclodextrin; WD $\alpha$ : 水分鿒缺(干旱) $+\alpha$-环糊精 Water deficit $+\alpha$-cyclodextrin

\section{3 讨论}

\section{1 干旱对谷子光合参数的影响}

干早导致作物光合速率降低 ${ }^{[7,28]}$, 而提高叶片净光合速率是提高干旱胁迫下作物产量的重要途径 ${ }^{[29-30]}$ 。 本研究中不同抗旱性谷子品种在干旱胁迫下呈现出不同的光合响应模式,总体表现为高光合速率对应较高的 籽粒产量, 这与前人研究结果相一致 ${ }^{[30]}$ 。光合速率的降低主要是由于气孔关闭导致的气孔限制和光合色素 的降解及合成受阻等造成的非气孔限制引起的 ${ }^{[31]}$ 。本实验中安 04 谷子叶片气孔导度下降幅度远大于豫谷 
1 号 (图 3), 说明安 04 降低的光合速率可能受到气孔限制的影响要大于豫谷 1 号。最大化学效率 $\mathrm{Fv} / \mathrm{Fm}$ 反 映光系统反应中心利用光能的最大能力, 是胁迫条件下光系统受损程度的判定标准之一 ${ }^{[32]}$ 。本研究中拔节 期两种水分条件下各品种 $\mathrm{Fv} / \mathrm{Fm}$ 并不存在显著性差异, 说明在胁迫初期光系统损害程度较轻; 而叶绿素含量 则出现显著性差异, 但其下降的幅度远小于开花期, 说明谷子叶片叶绿素含量轻微下降对光系统损伤影响较 小。开花期叶片净光合速率的下降可能是干旱诱导的叶绿素降解或合成受阻导致光系统损害程度和气孔限 制双重影响的结果; 而干旱诱导叶绿素降解或合成受阻可能与叶片的水分状况有关,如豫谷 1 号维持了相对 更高的叶片相对含水量, 提高叶片相对含水量有助于缓解干旱对作物植株的伤害进而提高其对干旱的耐受 能力 ${ }^{[33]}$ 。

\section{$3.2 \beta$-淀粉酶与改善谷子抗旱性}

干旱胁迫下,非结构性碳积累对植物响应胁迫具有重要作用 ${ }^{[34-35]}$ 。干旱胁迫下, 麻栋幼苗会提高整株非 结构性碳水平而提高叶片非结构性碳含量, 说明非结构性碳含量积累可能有助于与抗旱性的提高 ${ }^{[34]}$; 而马铃 薯则提高块茎中非结构性碳含量来缓解干旱胁迫导致的产量抑制 ${ }^{[35]}$; 因此, 叶片的非结构性碳积累是植物抗 性提高的重要因素之一。本研究中抗旱性较强的豫谷 1 号其功能叶片非结构性碳含量要高于安 04 , 并且干 旱胁迫显著诱导了豫谷 1 号非结构性碳积累, 这种在干旱胁迫下叶片非结构性碳急剧积累有可能是豫谷 1 号 维持较高光合速率及产量的重要机制之一。

淀粉是植物夜间新陈代谢所需的重要物质来源, 可溶性糖是植物呼吸作用的能量基础。长期干旱胁迫显 著提高了高粱叶片可溶性糖含量, 而淀粉含量虽有提高但并不显著 ${ }^{[36]}$; 本研究中抗旱性较强品种积累了更高 的可溶性糖, 说明可溶性积累可能是植物抵御干旱的重要途径。干旱胁迫下, 刺槐幼苗可能通过将叶片内临 时存储的少量淀粉转化成其直接利用的可溶性糖的方式, 以维持其正常的新陈代谢 ${ }^{[37]}$ 。 $\beta$-淀粉酶介导的淀 粉分解是可溶性糖形成的最主要来源。烟草中超表达枳 PtrBAM1 基因能有效提高 $\beta$-淀粉酶活性诱导蔗糖和 可溶性糖积累从而提高烟草对冷胁迫和冻害的抗性, 而柠檬 PtrBAM1 突变体则由于不能诱导蔗糖和可溶性 糖积累而降低其抗冷性 ${ }^{[38]}$ 。渗透胁迫导致拟南芥 $A t B A M 1$ 表达从而降低光照条件下淀粉积累提高可溶性糖 含量来适应水分变化 ${ }^{[39]}$ 。在茶树中,通过调控 $B A M$ 表达和活性来增强茶树对干旱等胁迫的抗性也已得到证 实 ${ }^{[40]}$ 。本研究中干旱胁迫下豫谷 1 号大幅度上调 $S i B A M 1 a$ 和 $S i B A M 1 b$ 基因表达,这可能是谷子叶片可溶性 糖积累的重要原因之一。

外源施用 $\beta$-淀粉酶活性专一性抑制剂 $\alpha$-环糊精进一步降低了干旱胁迫下谷子生物量积累, 并且可溶性 糖含量显著减少 (图 6), 说明 $\beta$-淀粉酶水解淀粉是谷子叶片可溶性糖积累的主要来源。此外, $\alpha$-环糊精显著 降低了叶片脯氨酸含量, 这与 Zanella 等 ${ }^{[41]}$ 研究发现 $\beta$-amylase 1 干旱胁迫下水分淀粉以维持脯氨酸合成的结 果相一致; 而可溶性糖和脯氨酸作为渗透调节物质对维持细胞正常的含水量和膨压具有重要作用 ${ }^{[42]}$ 。因此, 干旱胁迫诱导谷子 $\beta$-淀粉酶基因表达及 $\beta$-淀粉酶活性升高, 从而提高淀粉水解形成可溶性糖及渗透调节物 质脯氨酸的含量是谷子抗旱性改善的重要物质基础。

\section{4 结论}

干旱胁迫显著抑制了光合速率等相关性状, 进而影响谷子产量, 谷子可以通过提高 $\beta$-淀粉酶基因表达及 活性来适应干旱; 干旱胁迫下, 提高谷子 $\beta$-淀粉酶活性, 加强淀粉水解成可溶性糖, 进一步影响叶片脯氨酸的 合成对提高谷子抗旱性具有重要作用。抗旱性较强的谷子品种豫谷 1 号通过维持较高的叶片叶绿素含量、净 光合速率、光系统 II 最大化学效率及叶片相对含水量等途径, 从而获得较高的产量, 与 $\beta$-淀粉酶介导的淀粉 分解导致可溶性糖积累有重要关系。此外,干旱胁迫下,豫谷 1 号具有较高叶片蒸腾的情况下,依然维持高的 叶片相对含水量可能与其根系吸水能力有关, 需要进一步试验研究。 
致谢: 山西农业大学王兴春教授提供 xiaomi 系列材料。

\section{参考文献( References) :}

[ 1 ] Kang S Z, Zhang L, Liang Y L, Hu X T, Cai H J, Gu B J. Effects of limited irrigation on yield and water use efficiency of winter wheat in the Loess Plateau of China. Agricultural Water Management, 2002, 55(3): 203-216.

[ 2 ] Cattivelli L, Rizza F, Badeck F W, Mazzucotelli E, Mastrangelo A M, Francia E, Marè C, Tondelli A, Stanca A M. Drought tolerance improvement in crop plants: an integrated view from breeding to genomics. Field Crops Research, 2008, 105(1/2): 1- 14.

[ 3 ] Zhang C M, Shi S L, Liu Z, Yang F, Yin G L. Drought tolerance in alfalfa (Medicago sativa L.) varieties is associated with enhanced antioxidative protection and declined lipid peroxidation. Journal of Plant Physiology, 2019, 232: 226-240.

[ 4 ] Kaur K D, Jha A, Sabikhi L, Singh A K. Significance of coarse cereals in health and nutrition: a review. Journal of Food Science and Technology, $2014,51(8): 1429-1441$.

[ 5 ] Upadhyaya H D, Ramesh S, Sharma S, Singh S K, Varshney S K, Sarma N D R K, Ravishankar C R, Narasimhudu Y, Reddy V G, Sahrawat K L, Dhanalakshmi T N, Mgonja M A, Parzies H K, Gowda C L L, Singh S. Genetic diversity for grain nutrients contents in a core collection of finger millet (Eleusine coracana (L.) Gaertn.) germplasm. Field Crops Research, 2011, 121(1) : 42-52.

[ 6 ] 徐丽霞, 仪慧兰, 郭二虎, 张艾英. 干旱胁迫对谷子抽穗期生理生化和产量的影响. 山西大学学报: 自然科学版, 2016, 39(4): 672-678.

[ 7 ] Liu P, Yin L N, Deng X P, Wang S W, Tanaka K, Zhang S Q. Aquaporin-mediated increase in root hydraulic conductance is involved in siliconinduced improved root water uptake under osmotic stress in Sorghum bicolor L. Journal of Experimental Botany, 2014, 65(17) : 4747-4756.

[ 8 ] 袁小康, 周广胜, 王秋玲, 何奇瑾. 不同灌溉量夏玉米叶绿素含量的高光谱特征及其反演. 生态学报, 2021, 41(2): 543-552.

[ 9 ] 刘亚静, 张东升, 李萍, 宗毓铮, 郝兴宇. 大气 $\mathrm{CO}_{2}$ 浓度升高和干旱互作对谷子光合及抗旱生理特性的影响. 中国生态农业学报 (中英 文). (2021-01-21). https://doi.org/10.13930/j.cnki.cjea.200528.

[10] Dickman L T, McDowell N G, Grossiord C, Collins A D, Wolfe B T, Detto M, Wright S J, Medina-Vega J A, Goodsman D, Rogers A, Serbin S P, Wu J, Ely K S, Michaletz S T, Xu C G, Kueppers L, Chambers J Q. Homoeostatic maintenance of nonstructural carbohydrates during the 20152016 El Niño drought across a tropical forest precipitation gradient. Plant, Cell \& Environment, 2019, 42(5) : 1705-1714.

[11] 叶旺敏, 熊德成, 杨智杰, 朱益广, 张秋芳, 刘小飞, 林伟盛, 胥超, 张景, 杨玉盛. 模拟增温对杉木幼树生长和光合特性的影响. 生态学 报, 2019, 39(7): 2501-2509.

[12] Zhen F X, Zhou J J, Mahmood A, Wang W, Chang X N, Liu B, Liu L L, Cao W X, Zhu Y, Tang L. Quantifying the effects of short-term heat stress at booting stage on nonstructural carbohydrates remobilization in rice. The Crop Journal, 2020, 8(2): 194-212.

[13] Gucci R, Moing A, Gravano E, Gaudillère J P. Partitioning of photosynthetic carbohydrates in leaves of salt-stressed olive plants. Functional Plant Biology, 1998, 25(5): 571-579.

[14] 熊炳霖, 王釒金月, 陈道钳, 王仕稳, 殷俐娜, 邓西平. 苗期玉米叶片碳氮平衡与干旱诱导的叶片衰老之关系. 西北植物学报, 2016, 36 (3) : 534-541.

[15] Tang S, Li L, Wang Y Q, Chen Q N, Zhang W Y, Jia G Q, Zhi H, Zhao B H, Diao X M. Genotype-specific physiological and transcriptomic responses to drought stress in Setaria italica (an emerging model for Panicoideae grasses). Scientific Reports, 2017, 7(1) : 10009.

[16] Lata C, Bhutty S, Bahadur R P, Majee M, Prasad M. Association of an SNP in a novel DREB2-like gene SiDREB2 with stress tolerance in foxtail millet [Setaria italica (L.) ]. Journal of Experimental Botany, 2011, 62(10): 3387-3401.

[17] Li C, Yue J, Wu X W, Xu C, Yu J J. An ABA-responsive DRE-binding protein gene from Setaria italica, SiARDP, the target gene of SiAREB, plays a critical role under drought stress. Journal of Experimental Botany, 2014, 65(18) : 5415-5427.

[18] Li J R, Dong Y, Li C, Pan Y L, Yu J J. SiASR4, the target gene of SiARDP from Setaria italica, improves abiotic stress adaption in plants. Frontiers in Plant Science, 2017, 7: 2053.

[19] 余爱丽, 赵晋锋, 王高鸿, 杜艳伟, 李颜方, 张正, 郭二虎, 梁爱华. 两个谷子 CIPK 基因在非生物逆境胁迫下的表达分析. 作物学报, 2016, 42(2): 295-302.

[20] 许冰霞, 尹美强, 温银元, 裴帅帅, 柯贞进, 张涁, 原向阳. 谷子萌发期响应干旱胁迫的基因表达谱分析. 中国农业科学, 2018, 51(8)： $1431-1447$.

[21] 孙永刚, 凌腾芳, 王家杰, 徐戬, 宣伟, 汤国辉, 沈文遏. 外源一氧化氮供体硝普钠对小麦种子萌发早期 $\beta$-淀粉酶及其亚细胞分布的影 响. 作物学报, 2008, 34(9): 1608-1614.

[22] Yang Z R, Zhang H S, Li X K, Shen H M, Gao J H, Hou S Y, Zhang B, Mayes S, Bennett M, Ma J X, Wu C Y, Sui Y, Han Y H, Wang X C. A mini foxtail millet with an Arabidopsis-like life cycle as a $\mathrm{C}_{4}$ model system. Nature Plants, 2020, 6(9): 1167-1178.

[23] Kuhlgert S, Austic G, Zegarac R, Osei-Bonsu I, Hoh D, Chilvers M I, Roth M G, Bi K, Teravest D, Weebadde P, Kramer D M. MultispeQ 
Beta: a tool for large-scale plant phenotyping connected to the open PhotosynQ network. Royal Society Open Science, 2016, 3(10): 160592.

[24] 高俊风. 植物生理学实验指导. 北京: 高等教育出版社, 2006: 3-144.

[25] Barrs H D, Weatherley P E. A re-examination of the relative turgidity technique for estimating water deficits in leaves. Australian Journal of Biological Sciences, 1962, 15(3): 413-428.

[26] Pfaffl M W. A new mathematical model for relative quantification in real-time RT-PCR. Nucleic Acids Research, 2001, $29(9)$ : e45.

[27] Laby R J, Kim D, Gibson S I. The ram1 mutant of Arabidopsis exhibits severely decreased $\beta$-amylase activity. Plant Physiology, 2001, 127(4) : 1798-1807.

[28] Yan J K, Zhang N N, Wang X L, Zhang S Q. Differences in the physiological responses of Rht13 and rht wheat lines to short-term osmotic stress. Cereal Research Communications, 2020, 48(1): 41-47.

[29] Sun Y, Wang X, Wang N, Chen Y, Zhang S. Changes in the yield and associated photosynthetic traits of dry-land winter wheat (Triticum aestivum L. ) from the 1940s to the 2010s in Shaanxi Province of China. Field Crops Research, 2014, 167 (0):1-10.

[30] Yan J K, Zhang N N, Wang X L, Zhang S Q. Selection of yield-related traits for wheat breeding in semi-arid region. International Journal of Agriculture \& Biology, 2018, 20(3) : 569-574.

[31] 许耀照, 曾秀存, 张芬琴, 孙佳, 孙万仓, 武军艳, 方彦, 刘自刚, 孙柏林. 白菜型冬油菜叶片结构和光合特性对冬前低温的响应. 作物 学报, 2017, 43(3): 432-441.

[32] Woo N S, Badger M R, Pogson B J. A rapid, non-invasive procedure for quantitative assessment of drought survival using chlorophyll fluorescence. Plant Methods, 2008, 4: 27.

[33] 李琬婷, 宁朋, 王菲, 程小毛, 黄晓霞. 外源脱落酸对干旱胁迫下滇润楠幼苗生长及生理特性的影响. 应用生态学报, 2020, 31(5) : 1543-1550.

[34] 李亚楠, 张淞著, 张藤子, 魏亚伟, 李慧, 周永斌, 朱文旭, 殷有. 干旱-高钻对麻栋幼苗非结构性碳水化合物含量和分配的影响. 生态学 报, 2020, 40(7): 2277-2284.

[35] 苏亚拉其其格, 刹明寿, 陈玉珍, 韩康, 石晓华, 贾立国. 马铃薯非结构性碳水化合物含量对水分胁迫的响应. 植物生理学报, 2019, 55 (12) : 1839-1850.

[36] Chen D Q, Wang S W, Xiong B L, Cao B B, Deng X P. Carbon/nitrogen imbalance associated with drought-induced leaf senescence in Sorghum bicolor. PLoS One, 2015, 10(8) : e0137026.

[37] 杨斌, 彭长辉, 张贤, 刘伟国, 段敏, 王猛. 干早胁迫对刺槐幼苗叶片氮含量、光合速率及非结构性碳水化合物的影响. 应用与环境生物 学报, 2019, 25(6): 1261-1269.

[38] Peng T, Zhu X F, Duan N, Liu J H. PtrBAM1, a $\beta$-amylase-coding gene of Poncirus trifoliata, is a CBF regulon member with function in cold tolerance by modulating soluble sugar levels. Plant, Cell \& Environment, 2014, 37(12) : 2754- 2767.

[39] Valerio C, Costa A, Marri L, Issakidis-Bourguet E, Pupillo P, Trost P, Sparla F. Thioredoxin-regulated $\beta$-amylase (BAM1) triggers diurnal starch degradation in guard cells, and in mesophyll cells under osmotic stress. Journal of Experimental Botany, 2011, 62(2) : 545-555.

[40] Yue C, Cao H L, Lin H Z, Hu J, Ye Y J, Li J M, Hao Z L, Hao X Y, Sun Y, Yang Y J, Wang X C. Expression patterns of alpha-amylase and beta-amylase genes provide insights into the molecular mechanisms underlying the responses of tea plants (Camellia sinensis) to stress and postharvest processing treatments. Planta, 2019, 250(1): 281-298.

[41] Zanella M, Borghi G L, Pirone C, Thalmann M, Pazmino D, Costa A, Santelia D, Trost P, Sparla F. $\beta$-amylase 1 (BAM1) degrades transitory starch to sustain proline biosynthesis during drought stress. Journal of Experimental Botany, 2016, 67(6) : 1819-1826.

[42] 陈琳, 张俪文, 刘子亭, 路峰, 冯光海, 颜坤, 韩广轩. 黄河三角洲河滩与潮滩芦苇对盐胁迫的生理生态响应. 生态学报, 2020, 40(6)： 2090-2098. 